\title{
O tratamento do substantivo e do adjetivo em livros didáticos: uma abordagem gerativa
}

\section{The treatment of nouns and adjectives in textbooks: a generative approach}

Camila Costa Rabello Mendes ${ }^{1}$ Helena da Silva Guerra Vicente ${ }^{2}$
1 Bacharela e licenciada em Letras - Português pela Universidade de Brasília. Endereço eletrônico: camilacrmendes@gmail.com.

2 Doutora em Linguística. Docente e pesquisadora do Departamento de Linguística, Português e Línguas Clássicas da Universidade de Brasília. Endereço eletrônico: helenaguerravicente@ gmail.com.

\section{Resumo}

Este artigo pretende mostrar como alguns pressupostos gerativistas podem ser utilizados para contribuir para uma abordagem mais reflexiva da gramática em sala de aula, enfatizando os conhecimentos que o aluno possui de sua língua antes mesmo de entrar na escola. Nossa pesquisa consiste na discussão de excertos dos Parâmetros Curriculares Nacionais (PCNs), bem como na investigação de dois livros didáticos de Língua Portuguesa do ensino fundamental. A análise se foca no estudo dos substantivos e adjetivos e ressalta a dificuldade em se delimitar uma fronteira entre essas duas classes de palavras, pois a variação nos critérios utilizados por livros didáticos para classificá-las e descrevê-las gera definições incompletas ou confusas. Com a apresentação da dificuldade em questão, esperamos encorajar mais reflexões no que concerne ao estudo da gramática na escola.

Palavras-chave: Parâmetros Curriculares Nacionais. Teoria Gerativa. Substantivo. Adjetivo. Livro didático.

\begin{abstract}
This paper aims to show how some principles of the generative grammar can be used to contribute to a more reflective approach to grammar in classrooms, emphasizing the student's previous knowledge of his/her language, even before entering school. Our research consists of the discussion of excerpts from the Brazilian National Curriculum Parameters (PCNs) as well as the analysis of two elementary school textbooks of Portuguese. Our analysis focuses on the study of nouns and adjectives and highlights the difficulties in establishing boundaries between these two parts of speech. The varying criteria used by the textbooks to describe and classify them result in incomplete or confusing definitions. We hope to encourage further reflection and debates concerning the study of grammar at school.
\end{abstract}

Keywords: Parâmetros Curriculares Nacionais. Generative Grammar. Noun. Adjective. Textbook. 


\section{Introdução}

Este artigo pretende mostrar como pressupostos gerativistas podem ser utilizados para contribuir para uma abordagem mais reflexiva da gramática em sala de aula, a partir da competência e do conhecimento prévio do aluno, por exemplo. Como fundamentação, serão analisados os Parâmetros Curriculares Nacionais do ensino fundamental, doravante PCNs, pois estes apresentam trechos que corroboram os conceitos em questão. Além disso, as classes de palavras, especificamente as do substantivo e do adjetivo, foram escolhidas como tema a ser analisado, para mostrar como os pressupostos defendidos aqui podem ser aplicados no ensino. Essa escolha se deve às problemáticas na identificação e distinção dessas duas classes, o que proporciona material para reflexões e discussões em sala.

Além dos PCNs, serão analisados manuais de linguística e gramáticas, como fundamentação teórica para o estudo do substantivo e do adjetivo. Também serão investigados dois livros didáticos do ensino fundamental, a fim de identificar a abordagem teórica adotada pelos autores, bem como verificar se os livros possibilitam o trabalho do professor a partir do conhecimento prévio do aluno. Os livros didáticos escolhidos para a análise foram: Português: Linguagens - $6^{\circ}$ ano, de William Roberto Cereja e Thereza Cochar Magalhães (2010); e Português na ponta da língua - $5^{a}$ série, de Lino de Albergaria, Márcia Fernandes e Rita Espeschit (2002), ambos aprovados pelo Guia de Livros Didáticos PNLD 2008 do Ministério da Educação. A primeira obra foi escolhida por ser adotada por muitas escolas do Distrito Federal, entre públicas e particulares, enquanto a segunda foi selecionada com base na resenha feita pelo PNLD.

\section{Apresentação do problema}

Analisando-se os PCNs, percebe-se que estes abrem espaço para a aplicação de pressupostos gerativistas no ensino. Uma questão enfatizada diversas vezes pelo documento é a do conhecimento prévio, que, segundo Vicente e Pilati (2012), promoveria um deslocamento do foco no "como se ensina" para o "como se aprende", considerando que o aluno já possui um amplo conhecimento sobre a língua antes de ingressar na escola. $\mathrm{O}$ foco no conhecimento forma diferenciada, como agente eliciador ${ }^{3}$ desse conhecimento, trazendo à consciência do aluno as informações que ele já possui, o que seria o ponto de partida para o desenvolvimento de novos conhecimentos na escola.

Além da análise dos PCNs, as classes de palavras, em especial o substantivo e o adjetivo, foram escolhidas como objeto de estudo devido à dificuldade em se delimitar uma fronteira entre essas duas classes, o que permite que sejam feitas discussões em sala de aula que propiciem a reflexão dos alunos. Conforme observado por Pinilla (2008), um problema verificado na sistematização das classes de palavras diz respeito às definições que os manuais e livros dão para cada uma, que nem sempre se baseiam nos mesmos critérios, gerando definições confusas. A autora, citando uma pesquisa feita por Neves (1990), mostra que "classes de palavras" é o tema que é mais priorizado pelos professores de ensino fundamental nas aulas de Língua Portuguesa, mas que, apesar disso, não é criteriosamente tratado, pois ora ocorre uma mistura de critérios, ora faltam critérios. Pretende-se verificar como o tema é tratado por manuais, gramáticas e livros didáticos, observando como essas classes de palavras são abordadas e quais são os critérios utilizados para sua descrição e distinção. Para averiguar a ideologia e os posicionamentos dos autores dos livros didáticos, serão utilizados os manuais do professor desses livros.

$\mathrm{O}$ artigo se estrutura da seguinte maneira: primeiramente, é feita uma pesquisa de trechos dos PCNs que abram espaço para a aplicação de pressupostos gerativistas em sala de aula; a seguir, descreve-se como o substantivo e o adjetivo são tratados e classificados pelos manuais e livros didáticos; por fim, analisa-se a abordagem dos livros didáticos, tendo em consideração que costumam adotar os preceitos dos PCNs, verificando-se se é possível utilizá-los a partir de uma perspectiva gerativista.

\section{Investigação dos Parâmetros Curriculares Nacionais}

Como discutido por Vicente e Pilati (2012), diversos trechos dos PCNs propiciam a aplicação de pressu-

\footnotetext{
3 "Eliciação" se refere a "uma técnica de ensino que corresponde ao ato de extrair dos alunos informação previamente conhecida, antes que a eles seja apresentado conteúdo novo" (VICENTE; PILATI, 2012, p. 11).
} 
postos teóricos gerativistas no ensino de Língua Portuguesa, como "faculdade de linguagem", "competência" e "criatividade", apesar de estes não serem explicitados no documento, à exceção do conceito de "competência" (ainda que a "competência" citada no documento não corresponda à noção chomskiana). No sentido chomskiano, a competência linguística se relaciona ao conhecimento inato que o falante de uma língua tem sobre sua gramática, e que precede a exposição do indivíduo ao ensino formal e sistematizado da escola. Os PCNs apresentam, em notas de rodapé, uma definição de competência linguística, além de outros dois tipos distintos de "competências": a discursiva e a estilística. Seguem as definições:

Competência discursiva refere-se a um "sistema de contratos semânticos” responsável por uma espécie de "filtragem" que opera os conteúdos em dois domínios interligados que caracterizam o dizível: o universo intertextual e os dispositivos estilísticos acessíveis à enunciação dos diversos discursos.

Competência linguística refere-se aos saberes que o falante/intérprete possui sobre a língua de sua comunidade e utiliza para construção das expressões que compõem os seus textos, orais e escritos, formais ou informais, independente de norma padrão, escolar ou culta.

Competência estilística é a capacidade de o sujeito escolher, dentre os recursos expressivos da língua, os que mais convêm às condições de produção, à destinação, finalidades e objetivos do texto e ao próprio gênero e suporte (PARÂMETROS CURRICULARES NACIONAIS, 1998, p. 23).

Apesar de o conceito de "competência linguística" apresentado aproximar-se do chomskiano, que será o adotado por este artigo, é pouco elaborado, e a "competência discursiva", associada à capacidade de produção textual, é a mais mencionada. A definição citada se distingue da chomskiana porque parece se referir à competência linguística como um conjunto de saberes aprendido em comunidade, e não como os conhecimentos inerentes a um indivíduo, próprios dele. Ressalta-se essa distinção porque os PCNs adotam uma visão sociointeracionista a respeito da língua, enfatizando seu uso na comunicação e interação social e cultural - uma perspectiva relevante, mas que não é a que se pretende explorar neste artigo.

Outra concepção que se destaca é a de conhecimento prévio, que, infere-se equivaler, no contexto do documento, aos conteúdos aprendidos na escola em séries anteriores, que vão sendo aprofundados nos anos seguintes. Porém, como apontado por Vicente e Pilati (2012), uma significação mais adequada para o conceito de "conhecimento prévio" vai além disso, e também corresponde, justamente, à competência linguística.

Tomando como base os pressupostos gerativistas, e considerando, portanto, que o aluno possui um conhecimento linguístico inato e internalizado, caberia ao professor tornar explícito esse conhecimento, "instrumentalizando o estudante a fazer uso consciente das estruturas e dos recursos gramaticais que possui" (PILATI et al., 2011, p. 400). Ou seja, o professor assumiria um papel de agente eliciador, estimulando o aluno a se tornar consciente das informações que já possui e, a partir delas, desenvolver novos conhecimentos na escola. Seguindo esse raciocínio, defende-se a ideia sustentada por Vicente e Pilati (2012) de que a escola não ensina gramática ao aluno, por este já ter conhecimentos das regras de sua língua à altura da idade escolar. O professor, então, deve direcionar o aluno a tirar suas próprias conclusões sobre a língua. Como vimos dizendo, tal proposta encontra apoio nos PCNs em algumas passagens, como a seguinte:

Em relação à escrita de textos, a prática de análise e reflexão sobre a língua permite que se $e x$ plicitem saberes implícitos dos alunos, abrindo espaço para sua reelaboração. Ela implica uma atividade permanente de formulação e verificação de hipóteses sobre o funcionamento da linguagem [...]. No caso da produção oral, essa prática é prioritariamente de explicitação do que os alunos sabem utilizar - mas não têm consciência de que o fazem e por que [...] (PARÂMETROS CURRICULARES NACIONAIS, 1997, p. 53, grifo nosso).

Embora os PCNs enfatizem o trabalho com a produção escrita, é possível adaptar trechos como esse de acordo com a visão defendida aqui: nesse excerto, fica claro que é incentivada a explicitação dos saberes implícitos do aluno, bem como um processo de aprendizagem reflexivo, a partir da "formulação e verificação de hipóteses sobre o funcionamento da linguagem". Como os PCNs deixam em aberto como deve ser feita essa explicitação de conhecimentos, encontra-se, nesse trecho, respaldo para a utilização da técnica da eliciação. Em outros trechos, verifica-se uma preocupação em possibilitar aos alunos que "perguntem sobre a linguagem" (PCNs, 1997, p. 67), bem como a afirmação de que "não é papel da escola ensinar o aluno a falar: isso é algo que a criança aprende muito antes da idade escolar" (PCNs, 1997, p. 38), corroborando a ideia defendida por Vicente e Pilati (2012) 
de que o papel da escola não é "ensinar" gramática. Ao invés de "ensinar" ao aluno a língua em que ele já possui competência, a função da escola é alfabetizá-lo, promover seu letramento e desenvolver sua capacidade de expressão oral e escrita (VICENTE; PILATI, 2012), bem como explicitar as normas, classificações e padronizações sobre as quais não possui conhecimento.

Apesar das passagens que favorecem a abordagem da gramática a partir do conhecimento linguístico do aluno, destaca-se o eixo USO $\rightarrow$ REFLEXÃO $\rightarrow$ USO, adotado pelos PCNs como organizador dos conteúdos de Língua Portuguesa, e que considera "a produção/recepção de discursos como ponto de partida para a reflexão e finalidade do ensino da língua" (PCNs, 1998, p. 34). Porém, defende-se aqui a proposta de Vicente e Pilati (2012), de que o "ensino" da língua deve ter, sim, a finalidade de produção e compreensão de textos, mas seu ponto de partida deve ser a reflexão sobre o conhecimento prévio do aluno a respeito de sua língua. As autoras sugerem que a organização dos conteúdos seja feita em função de um modelo em que a reflexão anteceda ao uso, em um eixo REFLE$\mathrm{XÃO} \rightarrow \mathrm{USO} \rightarrow$ REFLEXÃO $\rightarrow$ USO... Essa proposta, bem como a concepção do professor como agente eliciador de conhecimentos linguísticos, e o foco na reflexão sobre aquilo que o aluno já sabe servirão como princípios norteadores para as análises feitas neste artigo.

\section{0 tratamento do substantivo e do adjetivo em manuais de linguística e gramáticas}

A problemática a ser explorada refere-se, sobretudo, ao substantivo e ao adjetivo, e à dificuldade em se estabelecer uma fronteira entre essas classes de palavras. Será tomado como base, para as análises posteriores, o texto de Pinilla (2008), Classes de palavras, em que a autora propõe que a classificação e a distinção das classes de palavras devem basear-se em ao menos três critérios: o funcional, que se refere à função ou papel da palavra na oração; o mórfico, que diz respeito à estrutura do vocábulo; e o semântico, relacionado aos modos de significação extralinguístico e intralinguístico.

De acordo com essa proposta, a autora, baseada em um estudo das classes de palavras de um livro didático de ensino médio, propõe que os substantivos devem ser classificados da seguinte maneira (PINILLA, 2008, p. 178):
- Critério funcional: "palavra que funciona como núcleo de uma expressão ou como termo determinado".

- Critério mórfico: "palavra formada por morfema lexical (base de significação) e morfemas gramaticais".

- Critério semântico: "palavra que designa os seres ou objetos reais ou imaginários".

Já os adjetivos são classificados como a seguir:

- Critério funcional: "palavra que funciona como especificador do núcleo de uma expressão".

- Critério mórfico: "palavra formada por morfema lexical (base de significação) e morfemas gramaticais".

- Critério semântico: "palavra que especifica e caracteriza seres animados ou inanimados, reais ou imaginários, atribuindolhes estados ou qualidades".

Tal proposta se fundamenta em Camara Jr. (2009), que utiliza os três critérios em sua proposta de classificação dos vocábulos formais e a distribuição destes em classes fundamentais. Para o autor, o critério semântico e o mórfico estão estreitamente associados, já que o sentido (critério semântico) não pode ser analisado como um conceito independente, pois está associado a uma forma (critério mórfico) (GROOT, 1948 apud CAMARA JR., 2009, p. 77). Por estarem intimamente ligados, Camara Jr. (2009, p. 75) os une em um critério compósito que chama de morfossemântico, que deve ser o fundamento primário de classificação. Por meio dele, chega a uma divisão dos vocábulos formais em nomes, verbos e pronomes e apresenta uma definição semântica dos nomes como "seres" ou "coisas". Além dessa divisão morfossemântica, estabelece uma classificação funcional, que divide nomes e pronomes de acordo com sua função na comunicação, havendo nomes e pronomes com "função de substantivo" e "função de adjetivo". Segundo o autor, a função de substantivo é a do "nome ou pronome tratado como centro de uma expressão, ou 'termo determinado", enquanto a função de adjetivo é a de um nome ou pronome que é um "termo determinante" que "modifica um nome substantivo ou tratado como determinado" (BALLY, 1950 apud CAMARA JR., 2009, p. 78-79). Além disso, o adjetivo se 
caracteriza por concordar em gênero e número com o substantivo que determina.

Sautchuk (2010) apresenta uma análise detalhada a respeito das classes de palavras e utiliza os critérios "forma", "função" e "sentido", que, segundo a autora, estão estreitamente conectados no que diz respeito à explicação de qualquer fenômeno linguístico. A forma se refere aos elementos estruturais que compõem ou decompõem paradigmaticamente as palavras; a função se dá de acordo com a posição ocupada pelo vocábulo no eixo sintagmático; e o sentido é compreendido a partir de uma relação entre os dois anteriores, estando ligado, também, a fatores extralinguísticos. Portanto, seus critérios são, essencialmente, os mesmos utilizados por Pinilla (2008) e Camara Jr. (2009).

A autora faz uma crítica à utilização apenas do critério semântico na classificação das classes de palavras, mas não nega sua importância, e mostra que diversas ocorrências da língua podem ser explicadas tão somente por ele. Entretanto, segundo ela, as definições baseadas puramente no sentido podem ser extremamente falhas, ${ }^{4}$ e a gramática tradicional evoluiu menos justamente na tarefa de conceituar os três lexemas básicos: substantivo, adjetivo e verbo. A autora argumenta que a definição do substantivo apresenta um conceito muito abstrato e filosófico, como "ser", e que se persiste em definir o adjetivo como "a palavra que dá qualidade aos seres" (SAUTCHUK, 2010, p. 17), questionando o que seria, exatamente, "qualidade" e "ser". Outra definição para o adjetivo é "a palavra que delimita significados do substantivo", que também é um conceito confuso. A falta de clareza nessas definições ocorre devido à grande quantidade de palavras que indicam qualidade, como "beleza" e "inteligência", que mesmo assim não podem ser classificadas como adjetivos. Há também o problema de palavras como "feio" e "estúpido", que a autora questiona se qualificariam ou desqualificariam substantivos (SAUTCHUK, 2010, p. 16-17).

Em seguida, a autora comenta sobre os mecanismos mórficos e/ou sintáticos na classificação e identificação de classes de palavras. O caráter mórfico é o formal, ligado aos elementos estruturais das palavras, e

\footnotetext{
4 A autora argumenta que explicações de caráter formal e sintático são "mais confiáveis, uma vez que dispensam exigências subjetivas de análise”. Para ela, as características e mecanismos de caráter essencialmente morfossintático possibilitam reconhecer com mais segurança as palavras que constituem o sistema lexical aberto da língua (SAUTCHUK, 2010, p. 18).
}

o sintático diz respeito à relação grupal de uma palavra com outra(s) em um sintagma. Também ressalta que “a classificação das palavras que compõem principalmente o sistema aberto da língua, mas, em muitos casos, também o sistema fechado, depende muito de seu 'comportamento' na cadeia falada" (SAUTCHUK, 2010, p. 19). Por isso, não se pode dizer que determinada palavra será sempre um substantivo ou adjetivo, o que existe são características peculiares a determinadas classes de palavras, mórficas ou sintáticas, que permitem assegurar que a palavra pertence a esta ou aquela classe de acordo com um determinado contexto, pois a língua não funciona em relação a um único eixo.

Em relação ao substantivo, Sautchuk (2010, p. 20) afirma que "é o critério sintático que se mostra extremamente eficiente para sua identificação e posterior classificação, além de refletir um artifício já consagrado por qualquer falante." Para a autora, só são substantivos, em português, as palavras que podem ser antecedidas por um determinante, independentemente de serem "seres" ou não. O determinante é um morfema gramatical independente que não acrescenta conteúdo semântico ao substantivo, mas apenas identifica sua referência por meio da situação espaçotemporal ou estabelece seu número. Articula-se somente com substantivos, ou palavras que estejam funcionando como tal, em um dado contexto. Para a autora, o reconhecimento dos substantivos por meio dos determinantes é muito útil quando se trata de substantivos abstratos ou que não possam ser identificados evidentemente como "seres", e ainda mais prático no caso dos concretos. A importância dos determinantes é ressaltada quando a autora afirma que estes possuem uma força "substantivadora” tão forte que pode transformar qualquer palavra de qualquer outra classe em um substantivo.

Sobre os adjetivos, a autora afirma que, em português, somente são adjetivos as palavras que aceitam o sufixo "-mente", formando um advérbio nominal, com algumas exceções. ${ }^{5}$ Porém, como alguns advérbios assim originados podem "soar mal", a autora apresenta outro critério: "é adjetivo toda palavra variável em gênero e/ou número que se deixa anteceder por 'tão' (ou por qualquer intensificador [...])" (SAUTCHUK, 2010, p. 23). O mecanismo funciona até em contextos de adjetivação de substantivo:

\footnotetext{
5 As exceções são as palavras "primeiro", "segundo", "duplo" e "triplo", que são numerais.
} 
(1) Ele não é homem para isso. ( = Ele não é tão homem para isso) ${ }^{6}$

É preciso verificar, além disso, se a palavra sendo acrescida do intensificador é variável em gênero e/ou número e se está se articulando junto a um substantivo, pois os mesmos mecanismos também podem ser usados na identificação de advérbios.

A classificação das classes de palavras e a problemática do substantivo e do adjetivo também são abordadas por Perini (2009), mas sua análise profunda o leva a especificar oito traços distintivos. Para ele, "a distinção entre substantivos e adjetivos é tão pouco marcada que há razões para duvidar da existência de duas classes distintas" (PERINI, 2009, p. 321).

O primeiro traço apresentado pelo autor se refere à possibilidade de a palavra ser núcleo de um sintagma nominal [+NSN]. Para o autor, essa é a função mais típica dos substantivos da gramática tradicional; entretanto, a análise segundo esse critério, apenas, colocaria na mesma classe palavras que não são normalmente classificadas como substantivos, como nos exemplos:

(2) Ela comprou um PC.

(3) Os endividados vão ter um alívio com a nova lei.

(4) O verde está muito na moda.

(5) Vencer é meu objetivo.

(6) Velho em geral dorme pouco. (PERINI, 2009, p. 322).

As palavras destacadas não são substantivos de acordo com a classificação tradicional, mas inegavelmente exercem a função de núcleo do SN. Porém, Perini ressalta que esse é apenas um traço, sendo que o potencial das palavras se exprime por vários, e isso equivale a dizer que "a maioria das palavras pode exercer mais de uma função sintática” (PERINI, 2009, p. 322).

O segundo traço é a possibilidade de ser um modificador [+Mod], que seria uma função típica dos adjetivos, mas há situações como:

(7) Tenho um sobrinho fazendeiro. (PERINI, 2009, p. 323)

\footnotetext{
${ }^{6}$ Exemplo colhido em Sautchuk (2010, p. 23).

Palavras como fazendeiro "não são nunca classificadas como adjetivo" (p. 323), mas, como se pode observar, esta pode ter a função de modificador. Além disso, há as palavras que podem ser modificadores, mas não NSNs, e estas são sempre chamadas de adjetivos.

O terceiro traço apresentado por Perini é a possibilidade de a palavra ocorrer como pré-núcleo [+PN], e os itens marcados com essa característica podem se encaixar nos dois critérios anteriores. Perini (2009) organiza cinco grupos de acordo com os critérios mostrados até agora: $1^{\circ}$ : [+NSN, -Mod, -PN]; $2^{\circ}$ : [+NSN, +Mod, -PN]; $3^{\circ}:[+\mathrm{NSN},+\mathrm{Mod},+\mathrm{PN}] ; 4^{\mathrm{o}}:[-\mathrm{NSN},+\mathrm{Mod},-\mathrm{PN}] ; 5^{\circ}$ : [-NSN, +Mod, +PN]. O primeiro grupo abarcaria os itens de comportamento tipicamente substantivo. O quarto e o quinto compreenderiam os mais tipicamente adjetivos. Já o segundo e o terceiro grupos incluiriam itens de comportamento ambíguo, que podem ser substantivos por poderem ser núcleo de SN, mas também adjetivos, por poderem ser modificadores ou pré-núcleos em outros contextos.

Os traços restantes, exemplificados abaixo, consistem em verificar as palavras que:

- Podem ou não ser intensificadas [Int-], como em:

(8) Uma blusa [muito verde];

- Podem ocorrer como complemento do predicativo $[+\mathrm{CP}]$, um traço que só parece valer para os itens [+Mod], como em:

(9) Ernesto é irritante;

- Podem apresentar o traço [+NSN], mas não podem coocorrer com nenhum outro item do $\mathrm{SN}$, formando um $\mathrm{SN}$ por si sós, como em:

(10) Minha Patrícia/ a Patrícia/ aquela Patrícia.

Estes itens apresentam o traço [-T,SN];

- Apresentam a propriedade de desempenhar a função de predicativo $[\mathrm{Pv}]$. (PERINI, 2009, p. 325-326).

Todos os sete traços apresentados são de natureza sintática. O oitavo e último traço, isto é, a possibilidade de coocorrer com o sufixo superlativo “-íssimo”, e variantes 
“-rimo" e "-imo", como em "paupérrimo" e "facílimo", é de natureza morfológica (PERINI, 2009, p. 326). Com base nos oito traços, Perini estabelece sete grupos que formam a base de sua proposta de classificação. A partir deles, chega às seguintes definições: "Substantivos são, pois, todas as palavras que podem ser complementos do predicado e não podem ser nem modificadores nem predicativos; adjetivos são as palavras que podem ser complementos do predicado, e também modificadores e predicativos" (PERINI, 2009, p. 327). Por fim, a classificação final do autor divide os substantivos e adjetivos em classes e subclasses, organizando-os em um quadro, de acordo com os critérios. Segundo essa divisão, as classes de substantivos e adjetivos incluiriam alguns itens que não pertencem a essas classes de acordo com as definições tradicionais.

A proposta de Perini, conforme mencionado pelo próprio autor, difere muito do que sugerem as gramáticas tradicionais e é muito mais complexa, porém permite uma divisão mais minuciosa, que pode esclarecer um pouco a fronteira entre as duas classes de palavras. Devido a essa complexidade, recomenda-se a leitura da obra do autor para melhor compreensão. Apesar da relevância da proposta, esta pode não ser a mais adequada para o trabalho com o nível fundamental do ensino, que é o foco deste artigo, ao menos no que diz respeito às terminologias e aos traços utilizados pelo autor; entretanto, a análise de algumas questões apresentadas seria válida, como, por exemplo, a dos substantivos exercendo papel de modificadores, função típica dos adjetivos. Para o trabalho com o nível fundamental, usar mecanismos como os propostos por Sautchuk (2010), por exemplo, pode ser vantajoso, visto que os métodos da autora são mais simples, apesar de um tanto categóricos.

Por fim, para exemplificar a gramática tradicional, questionada pelos autores mencionados, citam-se Cunha e Cintra (2008). O substantivo é classificado como "a palavra com que designamos ou nomeamos os seres em geral” (CUNHA; CINTRA, 2008, p. 192). Os "seres" são mencionados como nomes de pessoas, de lugares, de instituições (concretos), e noções, ações, estados e qualidades (abstratos). Ou seja, é priorizado o critério semântico. Porém, os autores também classificam o substantivo funcionalmente, como "a palavra que serve, privativamente, de núcleo do sujeito, do objeto direto, do objeto indireto e do agente da passiva. Toda palavra de outra classe que desempenhe uma dessas funções equi- valerá forçosamente a um substantivo" (CUNHA; CINTRA, 2008, p. 191).

Quanto ao adjetivo, é descrito como um modificador do substantivo, que serve "para caracterizar os seres, os objetos ou as noções nomeadas pelo substantivo" (CUNHA; CINTRA, 2008, p. 259), indicando uma qualidade ou defeito, o modo de ser, o aspecto ou aparência, o estado. Além disso, serve para "estabelecer com o substantivo uma relação de tempo, de espaço, de matéria, de finalidade, de procedência, etc." Novamente, é priorizado o critério sintático.

Entretanto, Cunha e Cintra (2008, p. 260) mencionam que a relação entre substantivo e adjetivo é muito estreita, e que é comum existir uma única forma para as duas classes de palavras, só podendo ser feita a distinção na frase; os autores utilizam o exemplo "Uma preta velha" $\mathrm{x}$ "Uma velha preta" Para eles, a subdivisão dos nomes em substantivos e adjetivos obedece a um critério essencialmente sintático e funcional. Porém, isso não é elaborado.

\section{Descrição dos livros didáticos escolhidos}

Primeiramente, a estrutura dos livros didáticos será descrita brevemente. O livro Português: Linguagens - $6^{\circ}$ ano divide-se em quatro unidades, cada uma com três capítulos, divididos em seções menores, que podem variar de acordo com o capítulo. As seguintes seções são as mais importantes e encontradas em quase todas as unidades: Estudo do texto, Produção de texto e A língua em foco. A estrutura padrão de um capítulo é a seguinte:

\section{Estudo do texto:}

- Compreensão e interpretação

- A linguagem do texto

- Leitura expressiva do texto

- Trocando ideias

\section{Produção de texto}

\section{A língua em foco:}

- Construindo o conceito

- Conceituando

- Exercícios

- Semântica e discurso 
O segundo livro, Português na Ponta da Língua $5^{a}$ série, é organizado em cinco unidades temáticas, divididas em nove seções, cada uma em função de um texto. Estas são compostas pelas seguintes subseções: "De olho no texto", com foco na leitura e compreensão do texto; "Indo além", que sugere reflexões críticas sobre o texto lido, com propostas de atividades, comparações com outros textos e pesquisas, por exemplo; "Mãos à obra", que propõe a produção de textos orais ou escritos, em grupo ou individualmente; "Pense, use e abuse", que trabalha com os conhecimentos linguísticos. Além disso, no final do volume, há a seção "Se você quiser saber + sobre...", que apresenta sugestões de leituras relacionadas aos textos do livro, outras obras de autores presentes no volume, e sugestões de materiais em outras mídias, como áudio e vídeo. O livro possui uma estrutura um pouco diferente do anterior, pois a maioria dos conceitos e explicações é apresentada nas atividades propostas, não havendo uma separação clara entre teoria e exercícios.

Em Português: Linguagens, o estudo do substantivo é introduzido na Unidade 2, Capítulo 1, na seção "A língua em foco". Na subseção "Construindo o conceito", é apresentada uma tirinha em quadrinhos seguida de alguns exercícios. O manual do professor explica que a finalidade dessa subseção é "levar o aluno a construir o conceito gramatical, por meio de um conjunto de atividades de leitura, observação, comparação, análise e inferências", partindo da "observação de um fato linguístico em texto [...] ou de exercícios operatórios"; depois disso, sugere-se que "determinado aspecto seja observado e depois comparado a outros, para então se chegar ao conceito" (CEREJA; MAGALHÃES, 2010, p. 6). De acordo com essa descrição, percebe-se que há uma proposta que poderia se aproximar da eliciação, por buscar extrair o conceito do aluno. Porém, os autores sugerem que isso seja feito a partir dos textos e exercícios, o que poderia ou não envolver os conhecimentos que os alunos já possuem. Os exercícios dessa subseção são os seguintes:

1. a) Nessa tirinha, a moça não parece amedrontada com o Drácula. O que demonstra que ela está tranquila? A imagem dela, com as mãos juntas na frente do corpo, um olhar apaixonado e a afirmação de que seu desejo - o de ter o segredo de seu pescoço descoberto - foi realizado.

b) O Drácula não parece satisfeito com o alimento que encontrou. $\mathrm{O}$ que demonstra isso? Ele vomita.
2. Na tira, a palavra segredo tem sentidos diferentes para a moça e para o Drácula.

Qual o sentido de segredo na fala da moça? Na visão dela, o segredo era sua beleza, seu charme, seu pescoço bonito e bem tratado.

O que o Drácula considera segredo? O creme hidratante misturado com óleo de quiabo que tinha sido usado pela sua vítima, causandolhe desgosto.

3. Explique o título da tira, "Drácula chamando Hugo". O título faz referência ao vômito de Drácula. Hugo é uma palavra cujos sons lembram o de alguém vomitando. Professor: Se quiser, comente que Hugo é uma onomatopeia de vômito. (CEREJA; MAGALHÃES, 2010, p. 90)

Após essas questões, a subseção "Conceituando" menciona que, depois de ler a tira e responder às questões, o aluno pode "observar que, para identificar os seres ou nomear coisas, necessitamos de palavras: segredo, pescoço, creme, Drácula ${ }^{7}$, etc. Essas palavras são chamadas de substantivos" (CEREJA; MAGALHÃES, 2010, p. 91). A seguir, é apresentada a seguinte definição: "Substantivos são palavras que nomeiam seres - visíveis ou não, animados ou não -, ações, estados, sentimentos, desejos e ideias." Percebe-se que os exercícios citados, relacionados à tirinha, não trabalham exatamente com o substantivo e com o conceito introduzido, estando mais voltados para a interpretação dos quadrinhos, o que pode não se adequar à proposta de construção de concepções a partir da leitura de textos/resolução de exercícios.

Já nos exercícios da seção "Conceituando", pedese, por exemplo, que os alunos identifiquem substantivos presentes em um texto. Outra atividade propõe que o estudante escreva pelo menos três substantivos que nomeiem objetos usados por alguns profissionais, como médico, pintor e cozinheiro. O exercício seguinte pede que o aluno faça uma lista de sentimentos e sensações que já teve e diga a que classe de palavras eles pertencem; provavelmente para introduzir o conceito de substantivo abstrato que é apresentado logo adiante.

Ao apresentar a classificação dos substantivos, os autores explicam que há vários tipos, e que "[a]lguns nomeiam coisas, outros nomeiam pessoas ou sentimentos. [...] No estudo gramatical da língua, eles são classificados, isto é, organizados, de acordo com certas características

${ }^{7}$ Exemplos que os autores retiraram da tira em quadrinhos. 
que apresentam" (CEREJA; MAGALHÃES, 2010, p. 92). Os substantivos são, então, classificados em:

- Primitivos e derivados, que dão origem e se originam de outras palavras, respectivamente. Exemplos: telha e telhado.

- Simples, formados por apenas uma palavra, e compostos, formados por mais de uma. Exemplos: mesa e pontapé.

- Comuns, que se referem a todos os seres de uma espécie, e próprios, que nomeiam um ser em particular e por isso são grafados com letra maiúscula. Exemplos: $r a-$ paz e Drácula.

- Concretos, que nomeiam seres que não dependem de outro para existir, podendo ser reais ou imaginários, e abstratos, que denominam seres de existência não autônoma $^{8}$ e designam sentimentos, ações e qualidades. Exemplos: pescoço e alegria.

- Coletivos, que, mesmo estando no singular, transmitem a ideia de um grupo de vários seres da mesma espécie. Exemplo: manada. ${ }^{9}$

Os exercícios que seguem essa explicação trabalham com essas classificações, sugerindo, por exemplo, que o aluno forme substantivos compostos a partir dos citados pela questão, que faça a distinção entre concretos e abstratos, comuns e simples, e que identifique substantivos coletivos. A partir dessas definições, pode-se dizer que os autores parecem utilizar, exclusivamente, o critério semântico, enfatizando a função do substantivo como sendo a de nomear "seres". Na seção "Semântica e discurso", alguns exercícios tratam da ambiguidade envolvendo o vocábulo "homenagem" em um anúncio, em que essa palavra é usada no seu sentido original de "celebração" e, também, como nome de uma cidade. Uma das questões mostra que a ambiguidade semântica também gera uma ambiguidade gramatical; tal questão explora o uso de

8 O livro explica o que são os "seres que dependem de outros para existir", apresentando uma tirinha de Mauricio de Sousa em que há a frase "A fome é inimiga da perfeição". A fome "é sempre sentida por alguém", e a perfeição "existe em pessoas ou coisas" (CEREJA; MAGALHÃES, 2010, p. 93).

9 Todos os exemplos foram retirados de Cereja e Magalhães (2010, p. 92-93) uma mesma palavra como substantivo "comum" e como substantivo "próprio".

Já a explicação sobre o adjetivo é desenvolvida no capítulo seguinte (2) da mesma unidade, na seção "A língua em foco”. Porém, algumas noções são antecipadas em uma seção do capítulo anterior, "[O substantivo] $\mathrm{Na}$ construção do texto", em um exercício. Tal atividade, que trabalha com um texto em que são apresentadas as visões de mundo diferentes do ser humano e da formiga, pede que o aluno apresente os elementos da visão da formiga correspondentes aos da visão do ser humano citados pela questão. Alguns elementos que o aluno pode encontrar são "lindo palácio", "manso lago", “espada fina”, entre outros. O exercício pergunta, então, se alguma dessas palavras designa "sentimento, sensação ou qualidade" (CEREJA; MAGALHÃES, 2010, p. 96).

Na subseção "Construindo o conceito" do Capítulo 2, são propostos alguns exercícios, a partir da análise da foto de uma menina, relacionados ao conceito de adjetivo apresentado na subseção seguinte, "Conceituando", focando seu aspecto "caracterizador". Por exemplo, pede-se para descrever a menina, como está vestida, como é seu cabelo, qual seria seu estado emocional de acordo com a expressão de seu rosto. Ao contrário do que ocorre no tópico do substantivo, o conceito de adjetivo proposto pelos autores pode ser, de fato, introduzido a partir da reflexão desses exercícios.

Na subseção "Conceituando", é mencionado que, ao responder as questões, o aluno certamente empregou palavras que desempenham o papel de "caracterizar os seres", os adjetivos. O conceito apresentado é o seguinte:

Enquanto o substantivo é a palavra que nomeia os seres, o adjetivo é a palavra que modifica o substantivo, indicando tamanho, cor, tipo, beleza, defeitos, qualidades, enfim, as características do substantivo. Assim, as palavras que você usou para indicar as características relacionadas à menina, como a cor de suas vestimentas [...], os seus cabelos [...], a sua expressão [...], são adjetivos (CEREJA; MAGALHÃES, 2010, p. 111).

Também é introduzida a "locução adjetiva", como uma expressão formada por mais de uma palavra, que possui o mesmo valor de um adjetivo (CEREJA; MAGALHÃES, 2010, p. 112). Após isso, os adjetivos são classificados em:

- Simples, formados por apenas uma palavra. Exemplo: laranja madura. 
- Compostos, formados por duas ou mais palavras. Exemplo: política econômico-financeira.

- Pátrios ou gentílicos, utilizados para indicar procedência ou nacionalidade. Exemplo: vinho português..$^{10}$

Um dos exercícios que seguem essa explicação pede para que o aluno indique dois adjetivos que normalmente expressa $(\mathrm{m}) \mathrm{a}(\mathrm{s})$ característica(s) de alguns substantivos. Um dos exemplos do livro é: "faca - afiada, apropriada". Depois, outra atividade pede para que o aluno substitua as locuções adjetivas apresentadas por adjetivos correspondentes. Na seção "Semântica e discurso", no final do capítulo, há mais exercícios que tratam da locução adjetiva, mas não é mencionado que, nos exemplos apresentados, são formadas a partir de substantivos.

No tópico "[O adjetivo] $\mathrm{Na}$ construção do texto", um box com a pergunta "para que servem os adjetivos?" afirma que estes servem para modificar os nomes, atribuindo-lhes características, e que, da mesma forma que os substantivos, "contribuem para organizar o mundo em que vivemos" (CEREJA; MAGALHÃES, 2010, p. 115). Além disso, afirma que servem para exprimir impressões e sentimentos diante das coisas e das pessoas. De acordo com os conceitos apresentados, observa-se que o critério semântico também é o priorizado na descrição do adjetivo.

A questão do conhecimento prévio do aluno não é citada no manual do professor; nas páginas 3 e 4 , é mencionado o "conhecimento prévio" que o aluno possui a partir do título ou do gênero a ser trabalhado, como um dos meios que levam os alunos a desenvolver habilidades de leitura. Porém, tal concepção não corresponde ao conceito adotado por este artigo (relacionado à competência linguística), pois parece se relacionar aos conhecimentos textuais adquiridos por meio da leitura.

O segundo livro, Português na Ponta da Língua, apresenta a discussão sobre o substantivo na seção do Texto 2 da Unidade 1. Primeiramente, um exercício pede para que o aluno releia os dois textos apresentados na unidade até $\mathrm{o}$ momento e liste as palavras que dão nomes a animais, tanto as que dão nome a um só animal como as que dão nome à espécie. Logo a seguir, o seguinte conceito é apresentado:
Todas as palavras que dão nomes a animais são chamadas substantivos. Veja que o substantivo se escreve com maiúscula (é nome próprio) quando dá nome a um animal específico: Aldo, Astro, Lua. Quando dá nome a toda a espécie, o substantivo se escreve com minúscula: peixe, peixe-boi, frango (ALBERGARIA et al., 2002, p. 21).

Em seguida, o conceito de substantivo composto é apresentado por meio de alguns exercícios. Um deles pede para que o aluno cite, da lista formada anteriormente, os que são formados por mais de um elemento; a questão seguinte explica que estes são os substantivos compostos e pede para que se formem o maior número possível a partir de um grupo de palavras apresentado. Uma das questões seguintes afirma que, ao analisar as anteriores, o aluno pode concluir que o substantivo, além de dar nome a animais, pode dar nome a outras coisas, e pede para que se responda que coisas são essas. Segundo o manual do professor, esse é o momento para se ampliar a definição inicial e "mostrar que a função do substantivo é nomear (dar nome)" (ALBERGARIA et al., 2002, p. 25). Nesse exercício, percebe-se a tentativa de fazer com que o aluno desenvolva o conceito de substantivo a partir das respostas e reflexões feitas em questões anteriores, sendo uma possibilidade de explorar seu conhecimento prévio.

Na seção do texto 5, subseção "Pense, use e abuse", é citado um pequeno trecho em que há as palavras "macaquices" e "maluquices". O enunciado explica que esses substantivos terminam em "-ice", e que estas três letras finais formam um sufixo, que possui uma "função especial" que deve ser estudada nas três atividades seguintes. A primeira pede que o aluno escreva outros substantivos terminados em "-ice" e compare com os encontrados pelos colegas. Depois disso, devem-se analisar as características que as palavras encontradas possuem em comum; segundo o manual do professor, palavras terminadas em "-ice" costumam indicar qualidades ruins, com a rara exceção de "meiguice". O manual sugere explicar aos alunos que "sufixo é aquela terminação que aparece na formação de diversas palavras, acrescentando a elas uma mesma significação" (ALBERGARIA et al., 2002, p. 30). Propõe diferenciar, por exemplo, do "-ice" do nome "Alice", que não é um sufixo.

A seção do Texto 6 trabalha a questão da letra maiúscula como identificação de substantivos próprios, estudando palavras como "Dodô" e "Pato", que são personagens do texto. $\mathrm{O}$ manual sugere verificar com a turma 
a possibilidade do uso das maiúsculas como recurso para transformar substantivos comuns em próprios, além de propor que os alunos elaborem suas próprias definições de regras para o uso de maiúsculas, comparando com as de gramáticas. Uma discussão sugerida é: "se a gramática não estiver totalmente de acordo com o que o autor [do texto 6] faz, isto significa que o autor 'errou?" (ALBERGARIA et al., 2002, p. 32). Quanto a isso, o manual explica que é importante mostrar que o uso feito pelo autor é possível e tem uma função no texto. Em relação ao substantivo, verificam-se, portanto, algumas questões morfológicas ligadas à semântica, mas, em sua classificação, predomina o critério semântico.

Quanto à discussão a respeito do adjetivo, esta é apresentada na Unidade 2, subseção do Texto 8. O texto compara a descrição dos índios feita por Pero Vaz de Caminha e pelo livro O Guarani, de José de Alencar. As primeiras atividades trabalham justamente com essa descrição, e, na subseção "Pense, use e abuse", é mencionado que "[m]uitas palavras usadas para descrever o índio são adjetivos. $\mathrm{O}$ adjetivo tem a função de modificar o substantivo" (ALBERGARIA et al., 2002, p. 73). Em seguida, um exercício pede que sejam listados os adjetivos usados em uma questão anterior e que se digam quais substantivos esses adjetivos modificam. O manual do professor propõe que se explique que o adjetivo modifica o substantivo na medida em que restringe a significação dada a ele. Segundo os autores, o substantivo seria um termo genérico, que, quando acrescido de um adjetivo, tem seu campo de significação delimitado. Ainda de acordo com esses autores, muitas vezes, por meio do adjetivo utilizado, mostra-se uma "visão própria de olhar o mundo" (ALBERGARIA et al., 2002, p. 47), sendo essa uma explicação semântica. Portanto, na definição do adjetivo, também é priorizado o critério semântico, mas nota-se o uso do critério funcional, já que os autores se referem a sua função de "modificador" (embora apenas do substantivo).

O manual do professor faz menção ao conhecimento prévio que o aluno possui sobre a língua, considerando que "o ponto de partida para uma reflexão gramatical deve ser o conhecimento linguístico (essencialmente da língua falada) que o aluno traz. O aprendizado da língua implica reflexão, formulação de hipóteses e verificação ou não dessas hipóteses" (ALBERGARIA et al., 2002, p. 12). Essa afirmação se aproxima da visão que defendemos anteriormente, de que a reflexão gramatical deve partir dos conhecimentos que o aluno já possui sobre a língua, em contraposição à dos PCNs, que acredita que o ponto de partida deve ser a produção de textos. Além de se sustentarem na ideia de que a reflexão deve partir do conhecimento do aluno, os autores se apoiam na linguística textual (que também é base para a proposta de Português: Linguagens) e consideram que "[a] progressiva construção do conhecimento gramatical parte, portanto, do texto, sem isolar interpretação, reflexão e produção" (ALBERGARIA et al., 2002, p. 12). Também defendem que, no trabalho de sistematização gramatical, deve-se considerar o desenvolvimento cognitivo do grupo de alunos, e que, para que a metodologia de ensino seja bem sucedida, "é preciso trabalhar com critérios de seleção e ordenação das questões linguísticas a serem exploradas: conhecimentos prévios da língua, utilidade, necessidade e oportunidade de uso dessas questões." Portanto, apesar da importância dada à reflexão a partir do texto, é evidente que os autores também valorizam e incentivam a reflexão a partir dos conhecimentos dos alunos.

\section{Análise dos livros didáticos e conclusões}

Como observado a partir da descrição do conteúdo dos livros, tanto na abordagem do substantivo, quanto na do adjetivo, ambos parecem favorecer o critério semântico. Apesar disso, nos manuais do professor, percebe-se que os autores possuem uma preocupação em abordar os demais critérios e outras questões relativas a essas classes de palavras. Essa divergência é apontada por Pinilla (2008, p. 172), que percebeu, em sua pesquisa, que há uma concordância entre os autores de livros didáticos de que é importante considerar as palavras de acordo com seus três aspectos, mas que, na maioria dos casos, a classificação se apoia basicamente na semântica.

Os autores dos livros demonstram se importar com um trabalho em sala de aula que não se restrinja ao âmbito da gramática normativa. No manual de Português: Linguagens, ao discorrerem sobre a proposta da seção "Conceituando", Cereja e Magalhães (2010, p. 6-7) apresentam seu posicionamento:

Sabemos que muitos conceitos da gramática normativa, como sujeito e advérbio, entre outros, são discutíveis e requerem uma revisão urgente por parte dos especialistas [...] Contudo, pela falta de outro modelo consensual, melhor e mais bem acabado, preferimos trabalhar com categorias consagradas e, sempre que possível, 
chamar a atenção do aluno para a incoerência do modelo gramatical ou para a existência de pontos de vista diferentes sobre o assunto. [...] Por esta razão, entendemos que, sobretudo nesta etapa de aprendizagem, o professor não deve se preocupar com minúcias da descrição gramatical. Embora na subseção Exercícios sejam encontradas atividades de reconhecimento e classificação gramatical, a finalidade central do trabalho com a língua é outra: garantir um mínimo de metalinguagem que permita ao aluno dar saltos maiores do ponto de vista semântico ou discursivo.

Como um exemplo, os autores mencionam que, para notar que um substantivo desempenha papel de adjetivo em um determinado contexto, é necessário que o aluno tenha, primeiramente, se apropriado dos conceitos dessas duas classes e consiga distingui-los, sendo que tais conceitos não seriam um fim em si, mas sim um meio para reflexões mais produtivas (CEREJA; MAGALHÃES, 2010, p. 7). Na apresentação da seção "Semântica e discurso", explica-se que esta tem o objetivo de ampliar o estudo gramatical de uma forma mais reflexiva, a partir de questões semânticas ou enunciativas, sendo um dos exemplos citados "a variação de sentido do adjetivo de acordo com sua posição." Os autores também mencionam que sua proposta de "ensino da língua" procura alterar o enfoque tradicional dado à gramática, voltado à classificação; não visa eliminar esse tipo de conteúdo, mas redimensioná-lo a partir de diversas outras atividades, ligadas principalmente ao texto e ao discurso. Espera-se que o aluno "deixe de aprender apenas a descrever a língua e passe efetivamente a operar a língua como um todo."

Apesar da relevância dessas considerações de Cereja e Magalhães (2010), e de sua clara preocupação em desenvolver uma proposta diferenciada, isso não se concretiza por completo no material do livro, ao menos no que diz respeito aos tópicos estudados. Percebeu-se, nos exercícios, que é dado foco justamente à classificação dos substantivos e adjetivos (enfatizando sua divisão em simples, compostos etc.), e muitas das reflexões consistem em associar essas classificações ao contexto em que as palavras se encontram nos textos lidos. Os exemplos citados no manual, como a análise de substantivos desempenhando papel de adjetivos, ou a variação de sentido do adjetivo de acordo com sua posição, não foram percebidos no livro. Além disso, a conceituação dessas classes de palavras foi dada de acordo com um só critério,
Outro problema encontrado foi a escassez de passagens que favoreçam o uso da técnica de eliciação, visto que não são feitas menções ao conhecimento prévio do aluno como base para o trabalho em sala de aula e para a reflexão gramatical, ao menos no que se refere ao conhecimento gramatical prévio, pois, como observado, os autores consideram que os conceitos devem ser extraídos dos alunos mediante textos e exercícios, a partir do conhecimento que possuem acerca do gênero textual que está sendo trabalhado. A proposta do livro confere grande importância ao estudo do texto e dos gêneros, à leitura e à produção de textos, baseando-se nos PCNs. Não se desconsidera a importância dessa abordagem, mas, como o objeto deste estudo é a gramática, pode-se dizer que o material ainda poderia ser mais desenvolvido nesse quesito, visto que, apesar de os autores sugerirem uma abordagem gramatical diferenciada, os tópicos são tratados de forma transmissiva e expositiva. Essas lacunas no tratamento dado à gramática são mencionadas pelo PNLD, que destaca a leitura e a produção textual coletânea como "pontos fortes" da obra, e, como "ponto fraco", o "tratamento dos conteúdos morfossintáticos, que destoa do restante da proposta" (BRASIL, 2007, p. 145), justamente por esse caráter expositivo, que contraria a ideia de que se deve procurar extrair os conceitos e conhecimentos a partir do aluno, apesar de se verificar uma preocupação com a pesquisa e a discussão em sala de aula.

O segundo livro, Português na ponta da língua, também apresenta o problema de utilizar apenas o critério semântico para classificar os substantivos e adjetivos. No entanto, o manual do professor recomenda que, sempre que necessário, se sugira ao aluno a pesquisa em gramáticas, preferencialmente consultando mais de uma, a fim de comparar o tema analisado (ALBERGARIA et al., 2002, p. 24). Os autores alertam o professor a ficar atento a dois pontos: que as definições mesclam, muitas vezes, os critérios semântico, sintático e morfológico; e que "a definição nem sempre funciona", pois pode não "acolher" todas as palavras de determinada categoria, de forma que a identificação possa se dar por outros meios (p. 24). Apesar de as definições serem baseadas no critério semântico, é incentivada a pesquisa de outros conceitos, pelos próprios alunos.

Outro ponto a ser destacado encontra-se na apresentação, no manual do professor, da seção "Indo além". Os autores explicam que as atividades dessa seção pro- 
curam "estimular o estabelecimento de relações entre o conhecimento construído com a leitura do texto e o conhecimento que [o aluno] já possuía, resultado da sua vivência” (ALBERGARIA et al., 2002, p. 15). Também mencionam que privilegiam "a construção de conceitos feita pelos próprios alunos.” A partir dessa afirmação, em conjunto com o trecho citado anteriormente, em que os autores consideram que o ponto de partida para a reflexão é o conhecimento linguístico que o aluno traz, podese concluir que sua concepção de "conhecimento prévio" se aproxima da ideia de "informações que o aluno já possui sobre a língua" e não de "informações adquiridas ao longo dos anos escolares".

Destaca-se, também, a maioria dos princípios que os autores sugerem como norteadores para os trabalhos de sistematização gramatical:

- ver o estudo gramatical como um momento de reflexão, debates e questionamentos;

- não tomar esse estudo como absoluto, orientando-se pelo uso da língua em suas diversas modalidades;

- buscar a participação ativa do aluno, para que ele desenvolva um interesse científico pela língua;

- formular regra de uso da língua, a partir de generalizações;

- saber distinguir descrição de prescrição linguística. (ALBERGARIA et al., 2002, p. 12-13).

Como se pode observar, é dado valor à pesquisa, à investigação e ao debate em sala de aula. A proposta de incentivo à construção de conceitos a partir da articulação entre os conhecimentos dos alunos, a leitura dos textos e a resolução de exercícios pode ser aproximada do eixo REFLEXÃO $\rightarrow$ USO $\rightarrow$ REFLEXÃO $\rightarrow$ USO..., defendido por Vicente e Pilati (2012). Isso, em conjunto com uma abordagem do conteúdo menos expositiva, devido à discussão dos conceitos por meio dos exercícios, faz deste livro o mais favorável, entre os analisados, para a utilização da técnica de eliciação. Mesmo que os pressupostos gerativistas buscados não sejam encontrados de forma explícita nesta obra, há aberturas que possibilitam sua aplicação, assim como nos PCNs. Isso pode ser ob- servado, por exemplo, no exercício da página 25, citado anteriormente, que mostra que a construção do conceito de substantivo ocorre gradativamente, a partir das respostas dos alunos. Não se quer dizer que em Português: Linguagens não exista a possibilidade de se trabalhar com esses pressupostos. Como observado, esse livro também proporciona alguma abertura para isso, mas a proposta de Português na ponta da língua e a ideologia que seus autores apresentam no manual do professor aproximamse mais do que se defende aqui.

Em relação ao conteúdo gramatical em si, entretanto, alguns temas poderiam ser mais explorados, como a análise de substantivos e adjetivos a partir da construção da frase. Nenhum dos livros aborda, por exemplo, a questão da posição das palavras, que pode trazer ambiguidades e dificultar a distinção entre essas duas classes, e não é investigada a complexidade de se estabelecer uma fronteira clara entre elas.

\section{Considerações finais}

Este artigo procurou mostrar como alguns pressupostos gerativistas podem contribuir para um trabalho em sala de aula que incentive a reflexão e a pesquisa, se distanciando dos métodos tradicionais que "ensinam" a gramática de forma expositiva. Considera-se que o aluno já tem conhecimento da gramática de sua língua antes de entrar na escola, e esta deve ensinar aquilo que ele não sabe, como normas e classificações, mas sempre tentando extrair as informações a partir desse conhecimento prévio. Por isso, destaca-se o papel do professor como agente eliciador, e do livro didático como ferramenta que propicie a aplicação desses pressupostos em sala de aula.

Foi encontrado respaldo para isso nos PCNs, que, apesar de sugerirem que o estudo da língua deve partir da produção, recepção e compreensão de textos, também apresentam trechos que corroboram a ideia de que os conhecimentos implícitos dos alunos e a aprendizagem com base na reflexão devem ser valorizados. Nos livros didáticos analisados, também foram encontradas metodologias e abordagens que favorecem a aplicação das ideias aqui defendidas. Português na ponta da língua foi o que mais se identificou com a proposta deste artigo, devido à valorização dos conhecimentos linguísticos prévios e à estruturação da obra, que se distancia dos modelos tradicionais por misturar exercícios e teoria sem uma divisão 
definida. Português: Linguagens também apresenta algumas aberturas para que se trabalhe com o conhecimento prévio e com a eliciação, mas sua metodologia mais expositiva dificulta isso.

Quanto à abordagem de substantivos e adjetivos, percebeu-se que há uma dificuldade nos livros didáticos em desenvolver esse tema. Isso se deve às definições baseadas quase que exclusivamente no critério semântico, o que é um problema, pois a definição deve se basear pelo menos nos três critérios mencionados. Como apontado por Pinilla (2008, p. 181), o conhecimento de como cada classe de palavras atua na organização e produção dos textos está vinculado a um ensino mais produtivo da língua; por isso, privilegiar apenas um dos critérios limita a forma como essas classes podem ser compreendidas. Outro problema percebido foi que os livros não abordam as ambiguidades e complexidades concernentes ao substantivo e ao adjetivo, que fazem com que uma fronteira entre eles não seja clara. Sabe-se como é difícil o desenvolvimento de um material didático que abarque todas as questões didáticas e linguísticas esperadas, e talvez essas questões não tenham sido consideradas tão relevantes pelos autores para o trabalho com esse ano do ensino fundamental. Por isso, considera-se a elaboração e sugestão de alguns exercícios que abranjam essas particularidades como assunto para um próximo trabalho.

\section{Referências}

ALBERGARIA, L.; FERNANDES, M.; ESPESCHIT, R. Português na ponta da língua, $5^{a}$ série. Belo Horizonte: Dimensão, 2002.

BRASIL. Ministério da Educação. Guia de livros didáticos PNLD 2008: língua portuguesa. Brasília: MEC, 2007.
BRASIL. Secretaria de Educação Fundamental. Parâmetros Curriculares Nacionais: língua portuguesa. Brasília: MEC/SEF, 1997.

BRASIL. Secretaria de Educação Fundamental. Parâmetros curriculares nacionais: terceiro e quarto ciclos do ensino fundamental: língua portuguesa. Brasília: MEC/ SEF, 1998.

CAMARA JR, J. M. Estrutura da Língua Portuguesa. 42. ed. Petrópolis: Vozes, 2009.

CEREJA, W. R. C; MAGAlHÃeS, T. C. Português: Linguagens, $6^{\circ}$ ano. São Paulo: Atual, 2010.

CUNHA, C.; CINTRA, L. F. L. Nova gramática do português contemporâneo. 5. ed. Rio de Janeiro: Lexicon, 2008.

PERINI, M. A. Gramática Descritiva do Português. 4. ed. São Paulo: Ática, 2009.

PILATI, E. et al. Educação linguística e ensino de gramática na educação básica. Revista Linguagem \& Ensino, Pelotas, v.14, n. 2, p. 395-425, jul./dez. 2011.

PINILLA, M. A. Classes de palavras. In: VIEIRA, S. R.; BRANDÃO, S. F. (Org.). Ensino de gramática: descrição e uso. São Paulo: Contexto, 2008.

SAUTCHUK, I. Prática de morfossintaxe: como e por que aprender análise (morfo)sintática. 2. ed. Barueri, SP: Manole, 2010.

VICENTE, H. G; PILATI, E. Teoria Gerativa e "ensino" de gramática: uma releitura dos Parâmetros Curriculares Nacionais. In: Verbum - Cadernos de Pós-Graduação, São Paulo, n. 2, p. 4-14, jul./dez. 2012. Disponível em:<http://revistas.pucsp.br/index.php/verbum/article/ view/12793/9279>. Acesso em: 3 fev. 2013. 